\title{
Inverted nipple and nipple reconstruction: The 'parachute' flap
}

\author{
Laurence Kirwan MD FRCS(Eng) FACS \\ New York Eye and Ear Infirmary, Norwalk and Greenwich Hospital, Norwalk, Connecticut, USA
}

L Kirwan. Inverted nipple and nipple reconstruction: The 'parachute' flap. Can J Plast Surg 1999;7(5):233-236.

The inverted nipple is a condition seldom discussed at length in standard works on breast surgery. The pathophysiology is a relatively short ductal system, which prevents the nipple from everting. Surgical procedures to correct the inverted nipple are divided into those that preserve ductal integrity and those that do not. Current techniques tend to be ineffective and are often complicated by a deformed nipple. A star-shaped flap is described which, when elevated by partial division of the ducts, looks like a parachute. Elevation allows collapse of the triangular flaps to form two concentric circles with a smaller diameter. The advantages of this technique are its simplicity, efficacy and lack of recidivism. The disadvantages are that it reduces the size of the areola and may result in a nipple that is too large. The method is also applicable to nipple reconstruction.

Key Words: Absent nipple; Breast reconstruction; Inverted nipple; Nipple reconstruction

\section{Mamelon invaginé et reconstruction du mamelon : le lambeau «parachute»}

RÉSUMÉ : L'invagination du mamelon est un état rarement discuté en profondeur dans les traités classiques de chirurgie du sein. La physiopathologie se caractérise par un système canalaire relativement court, qui s'oppose à l'éversion du mamelon. Les interventions chirurgicales visant à corriger l'invagination du mamelon sont divisées en celles qui conservent l'intégrité canalaire et celles qui ne la conservent pas. Les techniques actuelles semblent inefficaces et sont souvent compliquées d'une déformation du mamelon. On décrit un lambeau en forme d'étoile qui, lorsqu'on l'élève en divisant partiellement les canaux, ressemble à un parachute. Cette élévation permet aux lambeaux triangulaires de retomber pour former deux cercles concentriques de diamètre plus petit. Les avantages de cette technique sont sa simplicité, son efficacité, et une absence de récidive. Ses inconvénients sont qu'elle réduit la taille de l'aréole, ce qui peut résulter en un mamelon trop gros. On peut également utiliser cette méthode pour reconstruire le mamelon.

$\mathrm{T}$ he inverted nipple is a condition seldom discussed at length in standard works on breast surgery. An exception is the excellent review by Teimourian and Adham (1) describing the pathophysiology and history of surgical techniques for the correction of the inverted nipple.

The pathophysiology is a relatively short ductal system, preventing the nipple from everting. Surgical procedures to correct the inverted nipple are divided into those that preserve ductal integrity and those that do not. With respect to the former, the nipple is everted and the neck is tightened through a variety of techniques consisting of myotomy and

Correspondence and reprints: Dr Laurence Kirwan, 605 West Avenue, Norwalk, Connecticut 06850-4028 USA. Telephone 203-838-8844, fax 203-853-1862,fcps.lk@att.net skin excision. Wolfort and Marshall (2) added a V-Y skin advancement. With respect to the latter, the ducts are divided through either a bisection of the nipple (with internal nipple or breast flaps plicated to produce nipple eversion), or with lateral incisions and placement of de-epithelialized skin flaps below the nipple. I have found bisection of the nipple with internal flaps ineffective and often complicated by a deformed nipple. Attempts to simply divide the ducts and place internal plicating or purse-string sutures, as described by WeatherlyWhite (3), were also ineffective. I have not attempted the technique recommended by Teimourian and Adham (1) in which the ducts are divided and de-epithelialized flaps inserted beneath the nipple. A complete review of previously described techniques has already been presented by Teimourian and Adham (1). 


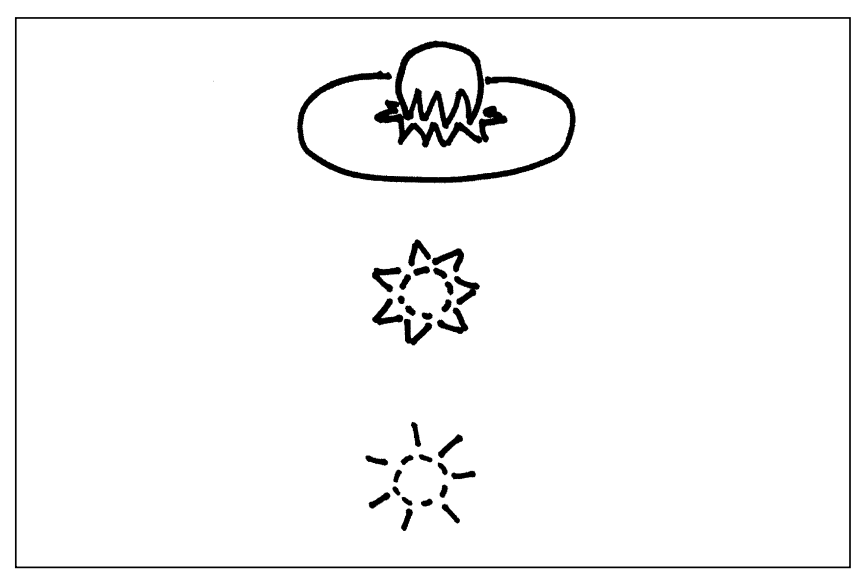

Figure 1) Illustration of the technique. Top Lateral view with collapse of triangular flaps to form two concentric circles. Middle Superior view with design of flaps. Bottom Superior view of result after closure

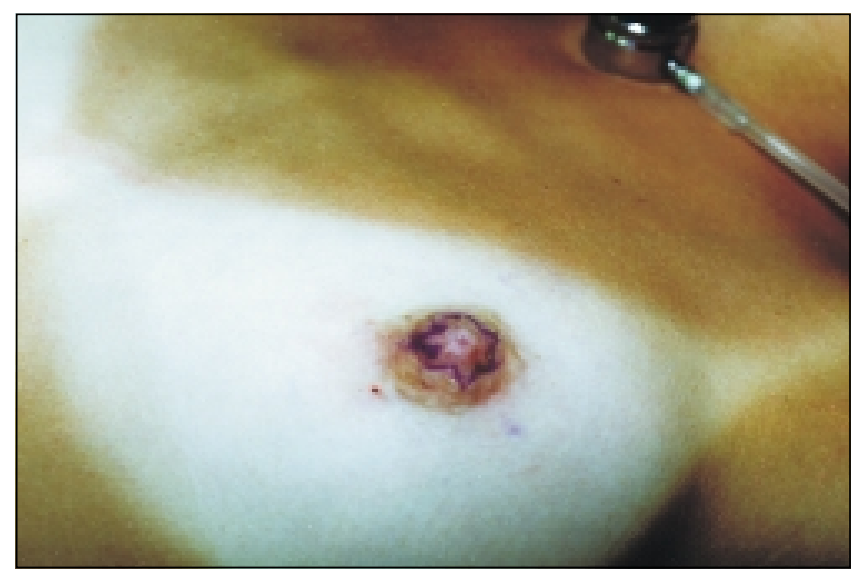

Figure 2) Treating nipple inversions. Preoperative design of multiple triangular flaps around nipple

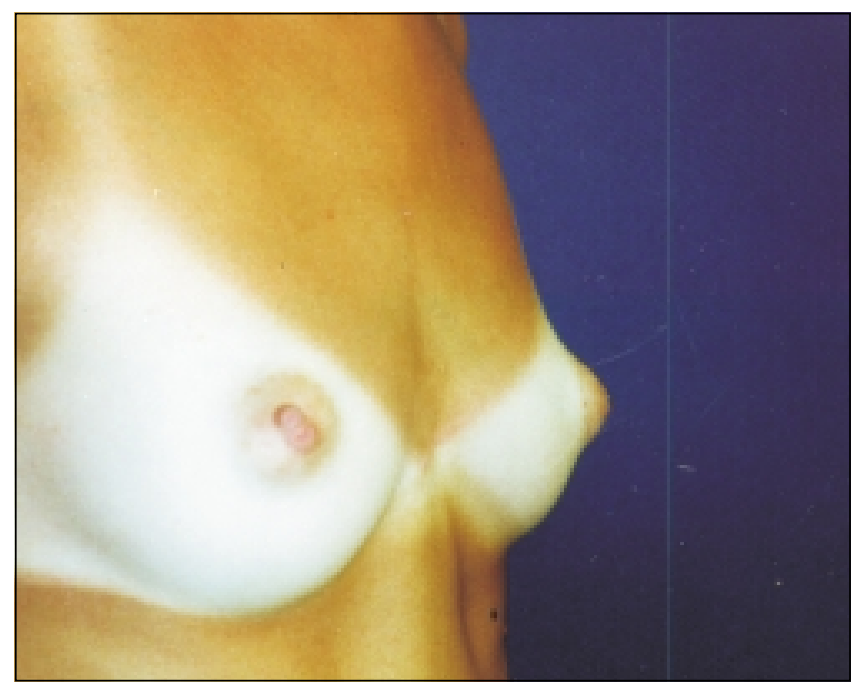

Figure 3) Treating nipple inversions. Preoperative lateral view

Because of the dissatisfaction with current methods, a star-shaped flap was designed which, when elevated by a partial division of the ducts, looks like a parachute. Elevation allows the collapse of the triangular flaps to form two concentric circles with a smaller diameter.

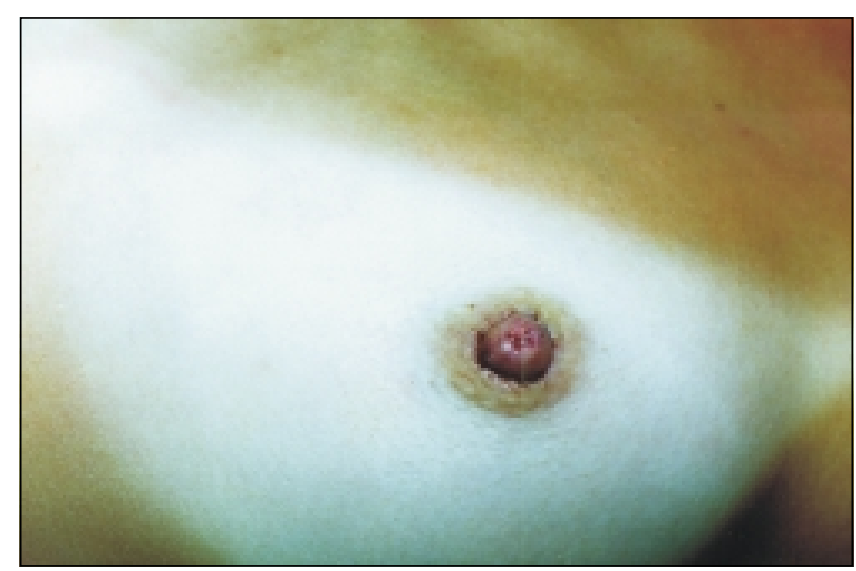

Figure 4) Treating nipple inversions. Postoperative frontal view

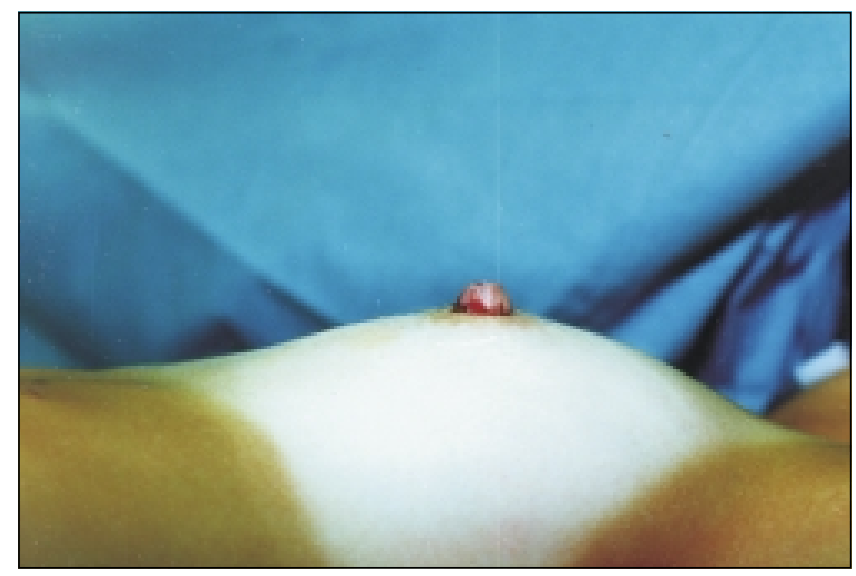

Figure 5 ) Treating nipple inversion. Postoperative lateral view

The method is also applicable to patients in which the nipple is absent as a result of scarring from previous surgery and after breast reconstruction with autogenous tissue.

\section{PATIENTS AND METHODS}

An illustration of the 'parachute flap' technique is seen in Figure 1. It shows: a lateral view with collapse of triangular flaps to form two concentric circles, and a superior view with the design of flaps and the result after closure.

If the nipple is inverted, it is elevated with a skin hook and held with a transfixion suture of 4-0 nylon. A circle is drawn on the nipple equivalent to its superior surface diameter, usually $1 \mathrm{~cm}$. Around this circle, multiple triangular flaps are drawn with 8 to $10 \mathrm{~mm}$ sides, depending on the desired height of the nipple and desired reduction in diameter of the areola (Figure 2). The larger the flaps, the fewer that are needed. Each flap is an equilateral triangle. The flaps are then incised with a number 11 blade, and the ducts are divided deeply so as to preserve the subcutaneous vascular pedicle. If a nipple reconstruction is being performed on autogenous tissue, the subcutaneous fat is divided at the periphery. The elasticity of the subcutaneous fat is sufficient to create elevation.

The apices of the nipple-based triangular flaps are 


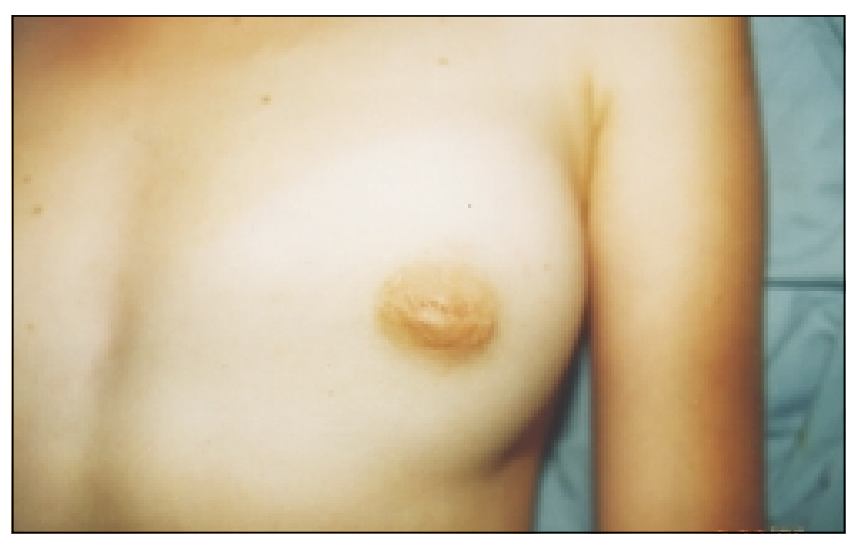

Figure 6) Treating absent nipple. Preoperative frontal view

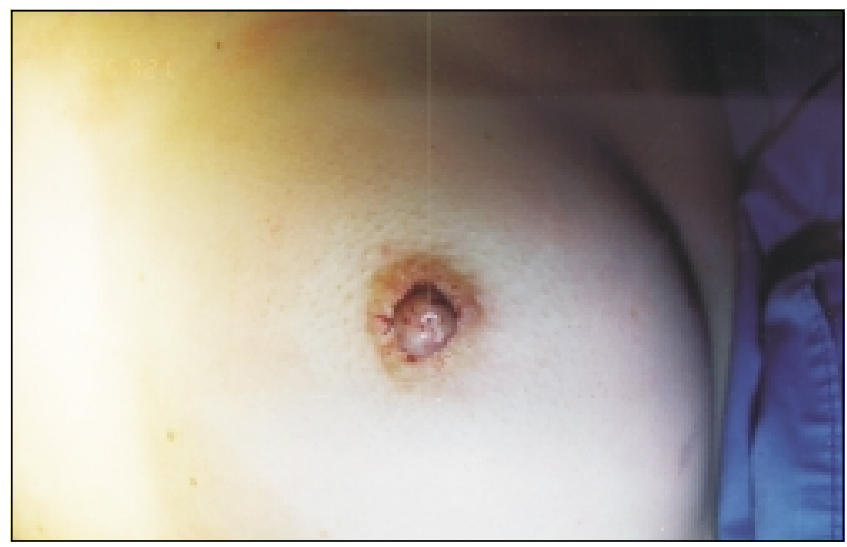

Figure 7) Treating absent nipple as a result of surgical scarring. Post operative frontal view

brought together by a purse-string sutures of 5-0 polygluconate as well as individual sutures of 5-0 chromic catgut between the sides of the flaps. The apices of the areola-based triangular flaps are also connected with a similar purse-string suture of 5-0 polygluconate as well as individual sutures of 5-0 chromic catgut between the sides of the flaps. The pursestring suture takes alternating bites of the apices of the areola-based triangles and the base of the subcutaneous pedicle to prevent retraction of the nipple. Complete closure is unimportant as long as a purse-string effect is created. If a skin graft is to be applied for areola reconstruction, the skin is de-epithelialized before elevating the flaps. A medicated gauze dressing is applied. After two to three days, the dressing is removed and Bacitracin (E. Fougera and Company, Melville, New York) ointment is applied until the wound is healed.

The steps involved in this procedure are further illustrated in Figures 3 to 8.

\section{DISCUSSION}

The advantage of this technique is its simplicity, efficacy and lack of recidivism. The disadvantages are that it reduces the size of the areola and that it may result in a nipple which is too

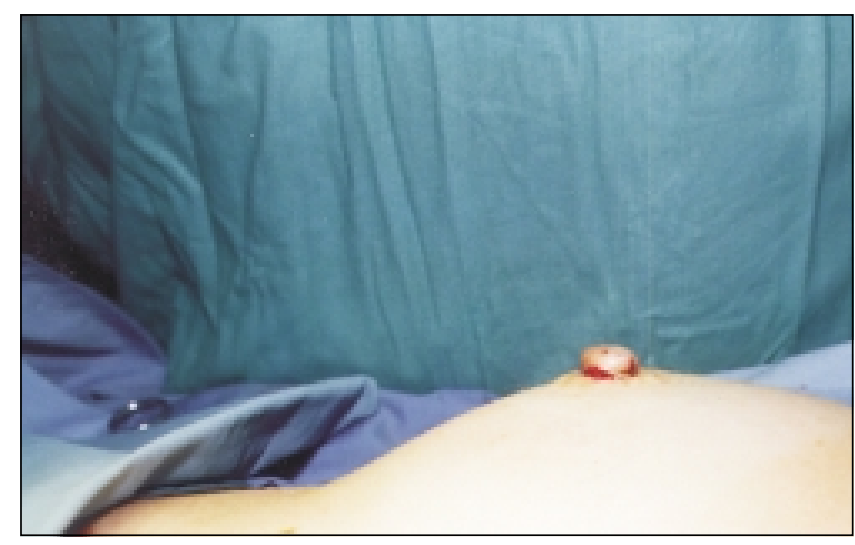

Figure 8) Treating absent nipple as a result of surgical scarring. Postoperative lateral view

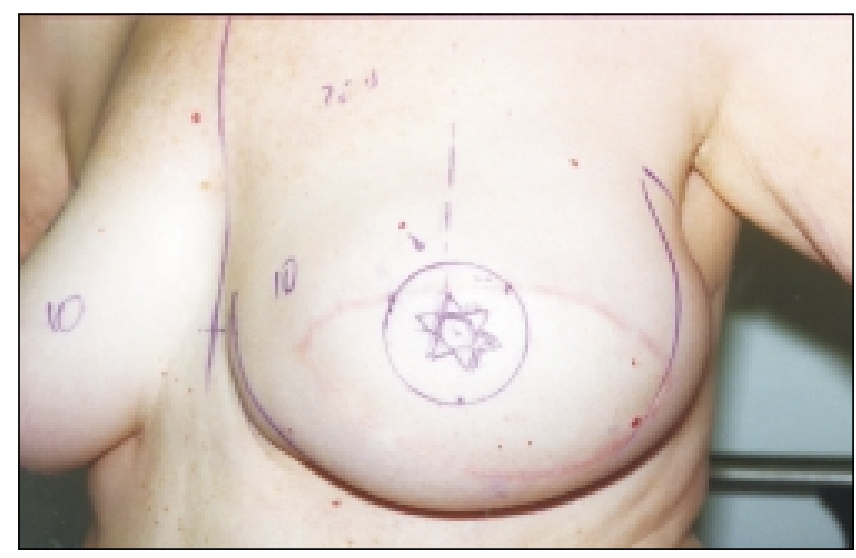

Figure 9) Breast reconstruction. Marking of parachute flap on breast reconstructed with transverse rectus abdominis muscle flap

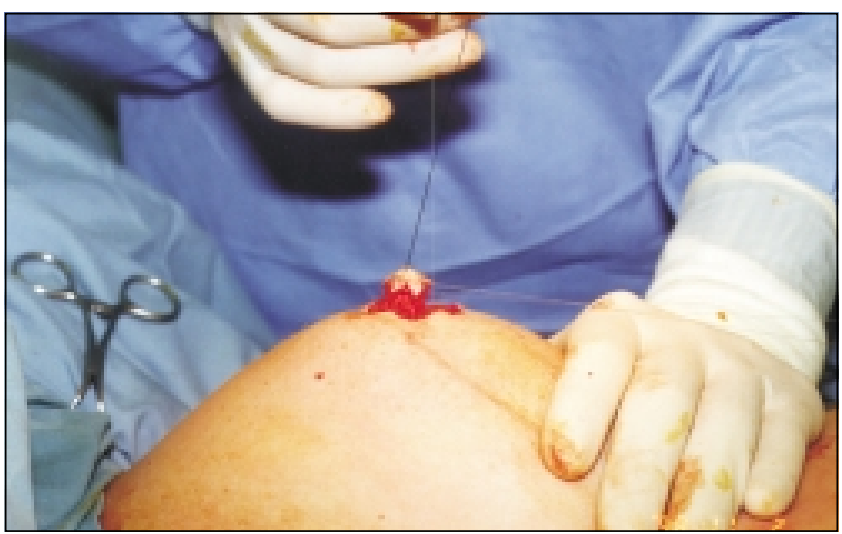

Figure 10) Breast reconstruction. Parachute flap elevated and held with stay suture of 5-0 Nylon

large. The method is applicable to cases of nipple inversion. It is also applicable to cases of nipple reconstruction after autogenous tissue breast reconstruction (Figure 9-11).

Because there is a circular scar around the base of the nipple, scar contracture increases rather than decreases nipple 


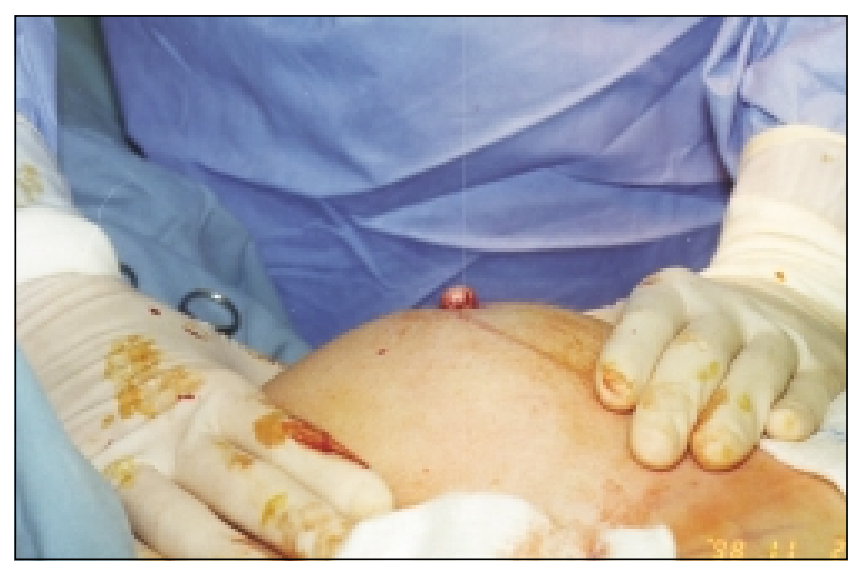

Figure 11) Breast reconstruction. Completion of reconstructed nipple

projection. Care should be taken not to tighten the outer purse-string suture too much or the circulation to the nipple may be compromised.

\section{CONCLUSIONS}

A simple method is described for the correction of the inverted nipple. Some of the ducts may be left intact, although this is not cited as an advantage of the technique. It is a reliable method, which takes approximately half an hour for each nipple; it produces a nipple of generous proportions and projection, without relapse. The method is also applicable in cases of absent nipple following surgical scarring and nipple reconstruction after breast reconstruction using autogenous tissue.

\section{REFERENCES}

1. Teimourian B, Adham MN. Congenital anomalies of the nipple and areola. In: Georgiade NG, Georgiade GS, Riefkohl R, eds. Aesthetic Surgery of the Breast, 1st edn. Philadelphia: WB Saunders, 1990:610-20.

2. Wolfort FG, Marshall KA. Correction of the inverted nipple. Ann Plast Surg 1978;1:294-7.

3. Weatherley-White RCA. Plastic surgery of the female breast, 1 st edn. Hagerstown: Harper \& Row Publishers, 1980:44-50. 